\title{
Analisis Penerapan Manajemen Persediaan Bahan Baku Arm Rear Brake Kyea dengan Metode EOQ
}

\author{
Ferry Utama Dwi Putra ${ }^{*}$, Apid Hapid Maksum ${ }^{2}$ Hamdani $^{3}$ \\ ${ }^{1,2,3}$ Teknik Industri, Fakultas Teknik, Universitas Singaperbangsa Karawang, Karawang \\ *Koresponden email: ferryutamadp@gmail.com
}

Diterima: 1 Desember 2021

Disetujui: 20 Desember 2021

\begin{abstract}
Inventory management is an essential aspect of supporting good production planning in company business activities. The implementation of inventory management in the company is a primary need. If there is a problem in the supply of raw materials, all the company's operational activities will be disrupted. Inventories in manufacturing usually consist of raw materials, semi-finished goods, and finished goods or final products. Inventories of arm rear brake materials for the production process often experience shortages due to immature controls. This study aims to determine the inventory control of rear arm brake raw materials using the Economy Order Quantity (EOQ) method at PT. Ciptaunggul Karya Abadi. Based on the discussion results, it was found that ordering raw materials was carried out two times a year with a total order of 621 pieces with 86 pieces of safety stock and will be ordered again when raw materials collected 21 pieces. Total Inventory Cost (TIC), which was initially Rp110.264.235,00, can be saved to Rp70.598.399,00 so that the total savings that occur are Rp39.674.899,00 which is equal to $33.26 \%$.
\end{abstract}

Keywords: PT. Ciptaunggul Karya Abadi, inventory management, economic order quantity, reorder point, safety stock.

\begin{abstract}
Abstrak
Manajemen persediaan adalah satu aspek penting penunjang perencanaan produksi yang baik dalam kegiatan bisnis perusahaan. Penerapan manajemen persediaan pada perusahaan merupakan kebutuhan primer apabila terjadi masalah dalam persediaan bahan baku semua kegiatan operasional perusahaan akan terganggu. Persediaan pada perusahaan manufaktur terdiri dari bahan baku (mentah), bahan setengah jadi dan barang jadi. Proses produksi perusahaan sering mengalami hambatan yang disebabkan adanya kekurangan persediaan bahan baku arm rear brake di gudang akibat perencanaan persediaan bahan baku yang belum optimal. Tujuan penelitian ini untuk menganalisa dan menentukkan pengendalian persediaan bahan baku arm rear brake yang optimal bagi perusahaan dengan menggunakan metode Economy Order Quantity (EOQ) di PT. Ciptaunggul Karya Abadi. Hasil yang didapatkan frekuensi pemebelian bahan baku yang optimal dilakukan sebanyak dua kali dalam setahun dengan jumlah pembelian sebanyak 621 lembar, bahan baku pengaman sebanyak 86 lembar dengan pemesanan kembali ketika bahan baku berjumlah 21 lembar. Total biaya persediaan bahan baku perusahaan yang semula sebesar Rp110.264.235,00 dapat dihemat menjadi Rp.70.598.399,00 sehingga penghematan yang terjadi sebesar Rp39.674.899,00 yaitu sebesar 33,26\%.
\end{abstract}

Kata Kunci: PT. Ciptaunggul Karya Abadi, manajemen persediaan economic order quantity, reorder point, safety stock.

\section{Pendahuluan}

Perencanaan produksi yang baik didukung oleh persediaan bahan baku yang memadai di gudang. Pengendalian persediaan adalah sebuah sumber daya perusahaan yang dimiliki juga termasuk aspek penting bagi keberlangsungan proses bisnis yang khususnya proses produksi suatu produk, dalam pengelolaannya perlu dilakukan secara proaktif [1]. Perusahaan harus memiliki kebijakan untuk mencapai tujuan yang diinginkan dalam mengantisipasi kekurangan persediaan. Membangun pengendalian persediaan bahan baku yang tepat dan pennggunaan biaya yang minimal. Setiap perusahaan baik itu manaufaktur maupun industri jasa di semua kegiatan memiliki tujuan untuk mencapai keuntungan maksimal semaksimal mungkin[2][3]. Manajemen persediaan merupakan salah satu aspek penting dan berpengaruh pada keberlangsungnya proses bisnis arm rear brake. Jika diibaratkan, persediaan pada perusahaan manufaktur merupakan kebutuhan primer. Dapat dikatakan begitu karena semua kegiatan operasional perusahaan akan terganggu apabila terjadi masalah dalam persediaan bahan baku. Manajemen persediaan bertujuan untuk 
mewujudkan biaya persediaan yang efisien, dengan cara melakukan sinkronisasi kebutuhan bahan baku pada rencana produksi dan menerapkannya saat pembelian bahan baku agar tidak terjadi kelebihan ataupun kekurangan.

Dalam sebuah perusahaan manufaktur, persedian terdapat seperti bahan baku, bahan setengah jadi atau work in process, dan barang jadi [4]. Penting bagi perusahaan untuk menentukan besarnya biaya persediaan karena berpengaruh terhadap keuntungan perusahaan. Perusahaan akan mengalami kerugian ketika terjadi kesalahan dalam penetapan kebutuhan bahan baku. Selain itu akan terjadi pembengkakan biaya penyimpanan dan pemeliharaan bahan baku yang disebabkan bahan baku yang menumpuk digudang. Selain itu, perusahaan pun akan mengalami penurunan keuntungan karena bahan baku yang menurun kualitasnya. Namun proses produksi di perusahaan dapat terhambat karena persediaan bahan baku terlalu sedikit [5]. Dari permasalahan tersebut, diharapkan dengan perencanaan kebutuhan baku akan dapat menghasilkan hasil yang optimal, yaitu biaya yang tepat dan minim, serta proses produksi yang lancar. Mengoptimalkan biaya persediaan bahan baku dapat mengggunaakan salah satu metode analisis yaitu Economic Order Quantity (EOQ). Penggunaan metode ini ditujukan untuk dapat menghasilkan ketersediaan bahan baku yang minimum namun memiliki kualitas yang baik dan minimalnya biaya. Penerapan EOQ pada proses perencanaan ketersediaan bahan baku dalam perusahaan bermanfaat dalam penghematan biaya pengeluaran persediaan bahan baku dengan mengurangi terjadinya kehabisan persediaan serhingga proses produksi perusahaan tidak terganggu [6]. Dalam pelaksanaannya, metode EOQ dinilai dapat memberikan penurunan biaya penyimpanan, menghemat ruang di gudang dan area kerja, serta memecahkan masalah persediaan untuk mengurangi resiko yang ditimbulkan oleh kelebihan bahan baku di gudang [7].

PT. Ciptaunggul Karya Abadi merupakan perusahaan yang bergerak dibidang dies, jigs, press part, tool, and other machinery industries. Dalam menunjang aktivitas produksi, maka perlu bahan baku yang cukup untuk mencapai hal tersebut. Oleh karena itu, perlu diperhatikan ketersediaan bahan baku agar tidak terjadi kekurangan ataupun kelebihan bahan baku. Pengiriman bahan baku dari supplier yang sering mengalami telat menyebabkan penundaan dalam proses produksi dan menyebabkan jadwal pengiriman barang jadi ke custumer menjadi telat karena terjadi kekurangan bahan baku di perusahaan. Penerapan persediaan bahan baku arm rear brake (kyea) sangatlah penting bagi perusahaan. Karena dalam mengontrol ketersediaan bahan baku sangatlah tidak mudah. Jika bahan baku terlalu banyak menumpuk maka akan mengakibatkan kerugian. Di perusahaan saat ini mengalami ketidakstabilan terhadap permintaan pada arm rear brake (kyea) yang tiap bulannya tidak kontinu. Sehingga ketidakmampuan perusahaan memenuhi permintaan dari konsumen, banyaknya bahan baku arm rear brake (kyea) yang sudah dipesan dan harus diproses menjadi produk jadi menumpuk digudang sehingga menyebabkan biaya penyimpanan meningkat, membuat harga tidak kompetitif dan menurunnya keuntungan yang didapat.

Untuk menentukan posisi penelitian saat ini, maka diambil beberapa penelitian terdaulu yaitu penelitian yang dilakukan [1] metode EOQ digunakan untuk mendapatkan kebijakan persediaan bahan baku atap spandedex. Serta mengoptimalkan total biaya persediaan perusahaan. Penelitian yang dilakukan [8] penggunaan metde EOQ ditujukan untuk mengetahui besaran pemesanan yang optimal supaya tidak terjadi kekurangan bahan baku kerupuk mentah dan kentang keriting dalam setiap pembelian bahan baku. Penelitian yang dilakukan [2] EOQ diterapkan untuk mencapai tujuan perusahaan yang diinginkan yaitu mendapatkan pengendalian persediaan bahan baku yang optimal. Penelitian yang dilakukan [6] EOQ dipakai untuk menganalisis kebutuhan bahan baku tepung terigu pada produksi roti. Penelitian yang dilakukan [9] EOQ diterapkan untuk menentukan kapasitas penyimpanan persediaan laptop di gudang PT. Gading Murni. Penelitian ini bertujuan yaitu perencanaan persediaan bahan baku arm rear brake kyea yaitu BJDC-SR (baja canai dingin) dengan membandingkan kebijakan perusahan dengan metode EOQ untuk mendapatkan kebijakan pemesanan bahan baku yang optimal bagi perusahaan.

\section{Metode Penelitian}

\section{Gambar 1.}

Pada metode penelitian ini digambarkan menggunakan flow chart seperti yang terdapat pada

a. Mulai, penelitian dilakukan mulai hari Senin, 08 Maret 2021 di PT. Ciptaunggul Karya Abadi.

b. Studi Pendahuluan, terdiri dari studi literatur dan studi lapangan penjelasan sebagai berikut: [10]

1) Studi literatur, yaitu membaca literatur berupa teori yang berhubungan dengan permasalahan dan mencari sumber tulisan yang pernah ditulis sebelumnya.

2) Studi lapangan, yaitu mempelajari kondisi objek penelitian secara langsung untuk mengetahui permasalahan yang ada. 


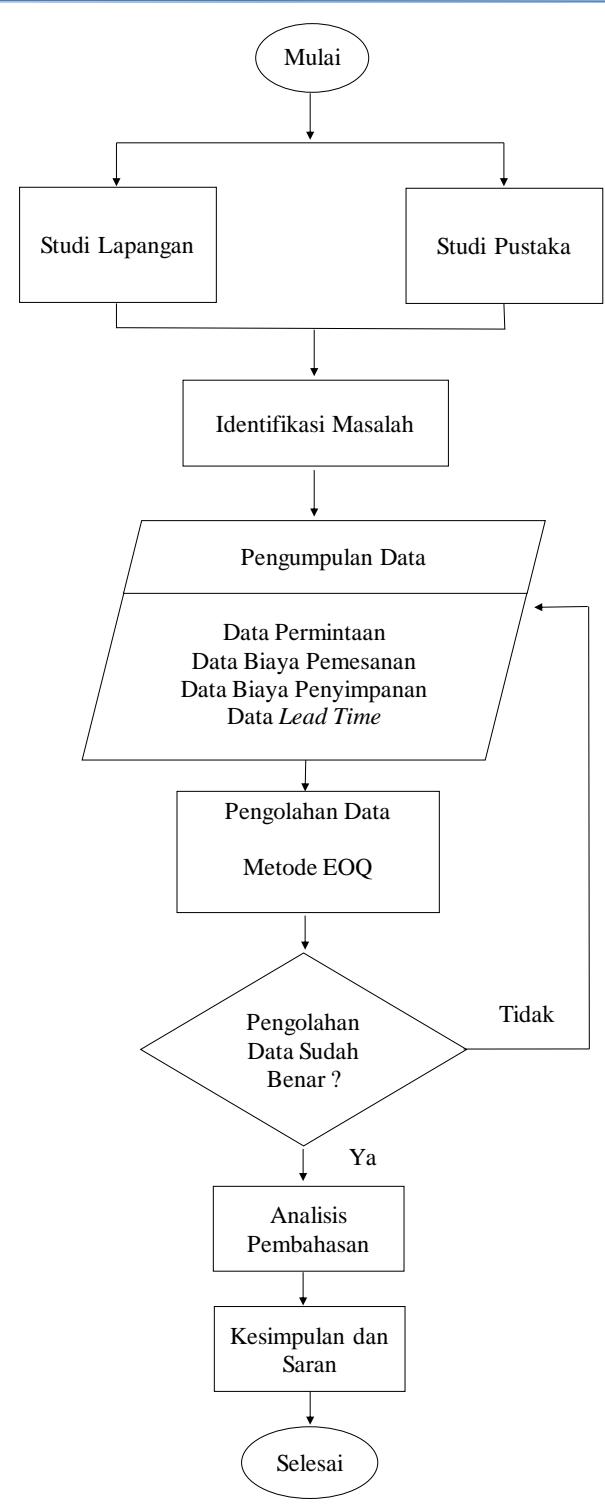

Gambar 1. Flow Chart Penelitian

Sumber: Hasil pengolahan data (2021)

c. Identifikasi Masalah, yaitu mencari tahu dan menyusun permasalahan yang ada dari latar belakang yang diuraikan. Terdapat masalah dalam penelitian ini yaitu kekurangan bahan baku dikarenakan supplier terlambat melakukan pengiriman dan terjadi penumpukan bahan baku yang sudah dibeli di gudang sehingga menyebabkan biaya penyimpanan meningkat.

d. Pengumpulan Data, yaitu proses mengumpulkan data dan informasi yang akan digunakan pada penelitian. Pada penelitian ini kebutuhan data berupa data sekunder. Data sekunder merupakan sebuah data yang dikumpulkan melelui informasi yang sudah ada sebelumnya seperti diperoleh dari data dokumen-dokumen perusahaan yaitu data jumlah BJDC-SR (baja canai dingin). Beberapa data yang dibutuhkan pada penelitian ini seperti permintaan bahan baku, biaya penyimpanannya, pemesanannya, lead time dan yang lainnya.

e. Pengolahan Data, yaitu menggunakan metode EOQ untuk mendapatkan kebijakan pemesanan bahan baku arm rear brake yang optimal bagi perusahaan.

f. Analisis dan Pembahasan, setelah didapatkan hasil melalui pengolahan data maka selanjutnya dianalisis dan dibahas maksud daripada hasil yang didapatkan tersebut. Hal ini bertujuan untuk mengetahui korelasi hasil dengan implikasi manajerial pada objek penelitian

g. Kesimpulan dan Saran yaitu setelah didapatkan hasil, maka dapat disimpulkan secara keseluruhan dari isi penelitian ini serta saran untuk penelitian kedepannya.

h. Selesai, penelitian telah selesai dilakukan. 


\section{Persediaan}

Barang disimpan dalam rangka pemenuhan kebutuhan pelanggan disebut sebagai persediaan dan termasuk salah satu kekayaan perusahaan [11]. Persediaan merupakan sumber daya perusahaan yang dapat berupa barang atau bahan. Barang dan bahan tersebut kemudian dapat dipergunakan ataupun dijual di waktu yang akan datang yang dapat berguna bagi perusahaan.

\section{Fungsi Persediaan}

Perusahaan mempunyai persediaan bahan baku yang dapat berguna dimasa depan. Menurut [12] fungsi persediaan barang pada perusahaan sebagai berikut:

a. Fungsi Decoupling

Pada fungsi yang pertama yaitu kebebasan dimiliki oleh pihak perusahaan internal ataupun eksternal dalam melakukan operasi. Pada fungsi ini, persediaan dapat memenuhi kebutuhan langganan tanpa menunggu supplier.

b. Fungsi Economics Lot Sizing

Pada fungsi ini perusahaan dapat melakukan produksi dan pembelian sumber daya dalam jumlah yang dapat memberikan penurunan pada biaya per unit namun tetap mempertimbangkan penghematan.

c. Fungsi Antisipasi

Dalam fungsi ini diharapkan permintaan pasar dapat diramalkan berdasarkan historis sebelumnya dengan tujuan menghadapi fluktuasi pada permintaan.

\section{Jenis- Jenis Persediaan}

Menurut ref. [13] jenis-jenis persediaan dibagi menjadi empat yaitu sebagai berikut:

a. Persediaan Bahan Mentah

Persediaan pertama adalah sebuah bahan yang telah dimiliki namun belum diproses. Hal ini dapat dimanfaatkan untuk memisahkan supplier dari proses produksi.

b. Pesediaan Barang Setengah Jadi

Persediaan kedua yaitu sebuah bahan yang telah dilakukan pemrosesan dalam aktivitas produksi hanya saja belum sampai pada tahap akhir.

c. Persediaan Pasokan

Jenis persediaan ini adalah sesuatu yang disediakan dalam rangka melakukan proses pemeliharaan, perbaikan, serta pengoperasian dengan tujuan menjaga mesin dan proses tetap berjalan.

d. Persediaan Barang Jadi

Bahan yang telah selesai di proses menjadi produk jadi dan tinggal dilakukan pengiriman ke konsumen. Barang jadi termasuk persediaan karena permintaan pelanggan tidak dapat diketahui dimasa yang akan datang.

\section{Metode Economic Order Quantity (EOQ)}

Menurut ref. [14] metode EOQ adalah sebuah metode persediaan yang dilakukan guna meminimalkan biaya secara keseluruahan pada proses penyimpanan dan pemesanan. Penggunaan metode ini didasarkan pada beberapa asumsi sebagai berikut:

a. Jumlah permintaan diketahui, konstan, dan independen.

b. Waktu tunggu diketahui yaitu waktu mulai pemesanan sampai penerimaan pesanan.

c. Persediaan sebuah pesanan datang dalam satu kelompok di suatu waktu.

d. Tidak adanya diskon pemesanan dalam jumlah banyak.

e. Biaya variabel terdiri biaya pemesanan dan biaya penyimpanan dalam waktu tertentu.

f. Kekurangan persediaan dapat dihindari dengan melakukan pemesanan pada waktu yang tepat.

Maka tahapan untuk mencari jumlah pemesanan berdasarkan asumsi yang telah disebutkan diatas sebagai berikut:

a. Pembuatan sebuag persamaan untuk mengukut biaya pemesanan.

b. Pembuatan sebuah persamaan untuk mengukur biaya penyimpanan.

c. Kemudian penentuan biaya pemesanan dan penyimpanan yang telah dibuat

d. Penyelesaian persamaan dengan menghasilkan jumlah bahan yang harus dipesan sudah optimal. Menyelesaikan persamaan dengan mendapatkan jumlah pemesanan yang optimal.

\section{Total Biaya Persediaan (Inventory Cost)}

Semua biaya yang digunakan pada semua tahapan proses pengadaan adalah termasuk pada total biaya persediaan. Kemudian perkiraan jumlah pembelian bahan tersebut dihitung dengan EOQ yang bertujuan untuk mencapatkan biaya persediaan yang mahal.

\section{Pesediaan Pengaman (Safety Stock)}

Persediaan ini merupakan sebuah konsep untuk meminimalisir kekurangan bahan baku yang diakibatkan karena permintaan yang tidak pasti. Persediaan stok pengaman dalam suatu perusahaan sangat 
penting karena berfungsi menghindari terganggunya proses produksi karena kekurangan bahan baku dan membantu keberlangsungan proses produksi.

Titik Pemesanan Kembali (Reorder Point)

Mengetahui waktu persediaan mencapai suatu atau tingkat tertentu untuk dilakukan pemesanan kembali. Apabila terjadi kesalahan dalam melakukan pemesanan ulang akan mengakibatkan penimbunan barang di gudang atau habisnya persediaan. Terdapat beberapa faktor yang dapat berpengaruh pada titik pesanan kembali, yaitu sebagai berikut:

a. Lead Time

Yaitu banyaknya waktu yang dibutuhkan untuk pesanan dapat datang dihitung dari sejak pesanan dilakukan. Apabila sering terjadi ketidaksesuaian jadwal dan terlambat, maka perunya stok pengaman yang banyak atau besar. Namun sebaliknya jika keterlambatan tidak sering terjadi, maka tidak perlu stok pengaman yang besar.

b. Stock Out Cost

Bahan baku yang terlambat datang dan juga suku cadangnya, akan mengakibatkan pengeluaran biaya, ini disebut sebagai Stock out cost. Stock out cost terdiri dari beberapa komponen biaya seperti hilangnya kesempatan mendapatkan keuntungan yang disebabkan karena pesanan tidak terpenuhi, biaya yang dikeluarkan untuk pemesanan darurat, dan lainnya. Apabila keadaan Stock out cost cenderung lebih besar dari carrying cost, maka perusahaan memerlukan stok pengaman yang besar.

c. Extra carrying cost

Kedatangan bahan baku dan suku cadang yang terlalu awal juga akan menyebabkan biaya yang disebut sebagai extra carrying cost. Hal ini karena kedatangan tersebut akan dapat berpegaruh pada biaya penyimpanan bahan baku.

\section{Hasil dan Pembahasan}

Pengumpulan data diperoleh dari bagian purchasing selama satu tahun yaitu pada periode $2020 \mathrm{di}$ PT. Ciptaunggul Karya Abadi. Bahan baku arm rear brake jenis kyea yang dihitung disini adalah BJDCSR 3,2 $\mathrm{mm}$ x $1.219 \mathrm{~mm}$ x $260 \mathrm{~mm}$ (bahan baku utama). Pada penelitian ini data diperoleh dari divisi terkait pada perusahaan yang berhubungan dengan kajian penelitian. Diantaranya terdiri dari biaya pemesanan dan juga penyimpanan seperti pada Tabel 3 dan Tabel 4.

Tabel 1. Data permintaan Arm Rear Brake (Kyea)

\begin{tabular}{cc}
\hline Bulan & Permintaan (Unit) \\
\hline Januari & 6.300 \\
Februari & 5.200 \\
Maret & 5.800 \\
April & 4.100 \\
Mei & 0 \\
Juni & 0 \\
Juli & 2.000 \\
Agustus & 0 \\
September & 2.400 \\
Oktober & 4.700 \\
November & 4.000 \\
Desember & 3.200 \\
Jumlah & 37.700 \\
\hline Sumber: PT Ciptaunggul Karya Abadi (2021)
\end{tabular}

Dari Tabel 1 diatas dapat diketahui bahwa permintaan produk berbeda-beda tiap bulannya sesuai kebutuhan yang berarti permintaan produk tidak continu. Data pemakaian bahan baku maka dapat diketahui jumlah kebutuhan bahan baku BJDC-SR 3,2 $\mathrm{mm}$ x $1.219 \mathrm{~mm}$ x $260 \mathrm{~mm}$ dari setiap lembar pelat baja dapat menghasilkan 42 potongan sebagai berikut:

Tabel 2. Pemakaian Bahan Baku

\begin{tabular}{cc}
\hline Bulan & Pemakaian (lembar) \\
\hline Januari & 150 \\
Februari & 124 \\
Maret & 138 \\
April & 98 \\
\hline
\end{tabular}




\begin{tabular}{cc}
\hline Mei & 0 \\
Juni & 0 \\
Juli & 48 \\
Agustus & 0 \\
September & 57 \\
Oktober & 112 \\
November & 95 \\
Desember & 76 \\
Jumlah & 898 \\
\hline Sumber: PT Ciptaunggul Karya Abadi (2021)
\end{tabular}

Biaya pemesanan adalah komponen biaya yang didapatkan dari aktivitas memesan sebuah barang dari pihak luar [15]. Bahan baku BJDC-SR 3,2 mm x $1.219 \mathrm{~mm}$ x $260 \mathrm{~mm}$ dikirim menggunakan kendaraan dari supplier yang dimana biaya pengiriman ditanggung oleh supplier. Diketahui kapasitas gudang bahan baku untuk BJDC-SR 3,2 mm x $1.219 \mathrm{~mm}$ x $260 \mathrm{~mm}$ sebanyak 5.000 kilogram. Adapun biaya pemesanan pada PT Cipta Unggul Karya Abadi dihasilkan dari administrasi dan telepon seperti pada Tabel 3.

Tabel 3. Biaya pemesanan PT. Ciptaunggul Karya Abadi

\begin{tabular}{ll}
\hline \multicolumn{1}{c}{ Jenis Biaya } & \multicolumn{1}{c}{ Jumlah Biaya / Tahun } \\
\hline Biaya Administrasi & Rp. 96.502 .929 \\
Biaya Telepon & Rp. 1.200 .000 \\
Jumlah & Rp. 97.702 .929 \\
\hline
\end{tabular}

Sumber: Hasil pengolahan data (2021)

Dilakukan perhitungan menggunakan rumus total biaya pesan per sekali pesan seperti berikut:

$$
\begin{aligned}
(\mathrm{S}) & =\frac{\text { Jumlah Biaya Pemesanan }}{\text { Jumlah Aktivitas Pemesanan }} \\
& =\frac{\text { Rp.96.502.929 }}{4} \\
& =\text { Rp. } 24.425 .732
\end{aligned}
$$

Jadi biaya pemesanan bahan baku BJDC-SR 3,2 mm x $1.219 \mathrm{~mm}$ x $260 \mathrm{~mm}$ sekali pesan adalah Rp. Rp.24.425.732,- per sekali pemesanan. Langkah berikutnya dilakukan perhitungan biaya penyimpanan yaitu biaya yang dibutuhkan dalam proses menyimpan bahan baku selama periode tertentu. Ada beberapa biaya yang dibebankan untuk penyimpanan bahan baku BJDC-SR 3,2 $\mathrm{mm}$ x $1.219 \mathrm{~mm}$ x $260 \mathrm{~mm}$ sebagai berikut:

Tabel 4. Biaya penyimpanan

\begin{tabular}{ll}
\hline \multicolumn{1}{c}{ Biaya } & \multicolumn{1}{c}{ Total Biaya } \\
\hline 2 Karyawan Gudang & Rp. 8.000 .000 \\
Listrik Gudang & Rp. 500.000 \\
Total Biaya/Bulan & Rp. 8.500 .000 \\
Total Biaya/Tahun & Rp. 102.000 .000 \\
\hline
\end{tabular}

Sumber: Hasil pengolahan data (2021)

Mengitung menggunakan rumus biaya penyimpanan bahan baku BJDC-SR 3,2 mm x $1.219 \mathrm{~mm}$ x $260 \mathrm{~mm}$ per lembar yaitu:

(H) $=\frac{\text { Jumlah Biaya Penyimpanan }}{\text { Jumlah kebutuhan Bahan Baku }}$

$$
\begin{aligned}
& =\frac{\text { Rp.102.000,000 }}{898} \\
& =\text { Rp. 113.586,-/Lembar }
\end{aligned}
$$

Jadi biaya penyimpanan bahan baku BJDC-SR 3,2 $\mathrm{mm}$ x $1.219 \mathrm{~mm}$ x $260 \mathrm{~mm}$ per lembar adalah sebesar 113.586,-/ lembar. 
a. Kebijakan PT. Ciptaunggul Karya Abadi

PT. Ciptaunggul Karya Abadi melakukan pembelian bahan baku BJDC-SR 3,2 mm x $1.219 \mathrm{~mm}$ x $260 \mathrm{~mm}$ sebanyak 4 kali dalam setahun dengan melalui pemasok yang tetap pada setiap pembeliannya.

1) Jumlah pembelian bahan baku

Dari banyaknya aktivitas pembelian bahan baku oleh PT. Ciptaunggul Karya Abadi kemudian dapat ditentukan rata-rata pembelian bahan pada BJDC-SR 3,2 mm x 1.219 mm x 260 mm setiap kali pesan seperti berikut:

$$
\begin{aligned}
(\mathrm{Q}) & =\frac{\text { Jumlah Kebutuhan }}{\text { Banyaknya Pemesanan }} \\
& =\frac{898}{4} \\
& =225 \text { Lembar }
\end{aligned}
$$

Jadi pembelian rata-rata bahan baku BJDC-SR 3,2 mm x $1.219 \mathrm{~mm}$ x $260 \mathrm{~mm}$ setiap kali pesan adalah sebanyak 225 lembar.

2) Jumlah Biaya Persediaan

Dari hasil perhitungan rata-rata pembelian bahan pada BJDC-SR 3,2 mm x $1.219 \mathrm{~mm} \times$ $260 \mathrm{~mm}$ kemudian dapat ditentukan jumlah biaya persediaan yang dikenakan pada PT. Ciptaunggul Karya Abadi sebelum penerapan EOQ. Dalam menghitung jumlah biaya persediaan, terlebih dahulu diketahui:
Jumlah kebutuhan bahan baku
(D) 898 Lembar
Rata-rata pembelian bahan baku
(Q) 225 Lembar
Biaya dalam sekali pesan
(S) Rp.24.425.732,-
Biaya penyimpanan per Lembar
(H) 113.586,-/ Lembar.

Perhitungan Total Biaya Persediaan (TIC) PT. Ciptaunggul Karya Abadi sebagai berikut:

$\mathrm{TIC}=\left(\frac{\mathrm{D}}{\mathrm{Q}} \mathrm{S}\right)+\left(\frac{\mathrm{Q}}{2} \mathrm{H}\right)$

$$
\begin{aligned}
\mathrm{TIC} & =\left(\frac{898}{225} \text { Rp. 24.425.732) }+\left(\frac{225}{2} \text { Rp. } 113.586\right)\right. \\
\mathrm{TIC} & =\text { Rp. } 97.485 .810,-+12.778,425,- \\
\mathrm{TIC} & =\text { Rp. } 110.264 .235-
\end{aligned}
$$

Jadi biaya persediaan untuk bahan baku BJDC-SR 3,2 mm x $1.219 \mathrm{~mm}$ x $260 \mathrm{~mm}$ di PT.

Ciptaunggul Karya Abadi adalah sebesar Rp. 110.264.235- selama dua belas bulan yang diperhitungkan.

b. Pengendalian persediaan menguunakan EOQ

Berdasarkan data yang didapatkan maka tahapan selanjutnya adalah dengan perhitungan EOQ. Dengan menerapkan metode EOQ diharapkan mampu mengidentifikasi kebutuhan ekonomis dalam melakukan pemesanan guna menekan biaya pada PT. Ciptaunggul Karya Abadi.

1) Perhitungan Bahan Baku
(D) 898 Lembar
(S) Rp.24.425.732,-
(H) Rp. 113.586,-/ Lembar.

Pemesanan BJDC-SR 3,2 mm x $1.219 \mathrm{~mm}$ x $260 \mathrm{~mm}$ yang ekonomis adalah:

$$
\begin{aligned}
& X=\frac{\sqrt{2 D . S}}{H} \\
& Q^{*}=\frac{\sqrt{2(898) \cdot(24.425 .732)}}{\text { Rp. } 113.586} \\
& Q^{*}=\sqrt{386.214,98} \\
& Q^{*}=621 \text { Lembar }
\end{aligned}
$$

Jadi pemesanan bahan baku BJDC-SR 3,2 mm x $1.219 \mathrm{~mm}$ x $260 \mathrm{~mm}$ yang ekonomis adalah 621 Lembar.

2) Frekuensi Pembelian Bahan Baku

Melalui penerapan metode EOQ kemudian dapat diidentifikasikan banyaknya proses pembelian bahan baku yang dapat dilakukan pada produk BJDC-SR 3,2 mm x $1.219 \mathrm{~mm}$ x 260 $\mathrm{mm}$. Banyaknya proses pembelian bahan baku yang dapat dilakukan berdasarkan EOQ, yaitu: $\mathrm{F}=\frac{\mathrm{D}}{\mathrm{Q} *}$ 
$\mathrm{F}=\frac{898}{621}$

$\mathrm{F}=1,45$ Dibulatkan 2

Jadi banyaknya pembelian 2 kali dalam setahun untuk bahan baku BJDC-SR 3,2 $\mathrm{mm} x$ $1.219 \mathrm{~mm} \times 260 \mathrm{~mm}$.

3) Jumlah Biaya Persediaan

Dari hasil yang didapatkan berupa rata-rata pemesanan dan banyaknya proses pemesanan yang dapat dilakukan melalui metode EOQ kemudian dapat dihitung jumlah biaya persediaan yang dikenakan. Kemudian perhitungan dilakukan menggunakan metode EOQ dengan diketahui:

(D) 898 Lembar

(Q) 621 Lembar

(S) Rp.24.425.732,-

(H) Rp. 113.586,-/ Lembar

PT. Ciptaunggul Karya Abadi perhitungan Total Biaya Persediaan (TIC) seperti berikut:

$\mathrm{TIC}=\left(\frac{\mathrm{D}}{\mathrm{Q}} \mathrm{S}\right)+\left(\frac{\mathrm{Q}}{2} \mathrm{H}\right)$

$\mathrm{TIC}=\left(\frac{898}{621}\right.$ Rp. 24.425 .732$)+\left(\frac{631}{2}\right.$ Rp. 113.586 $)$

$\mathrm{TIC}=\mathrm{Rp} .35 .320 .945,8+\mathrm{Rp} 35.268 .453$

TIC $=$ Rp. 70.589.399,-

Jadi banyaknya biaya untuk persediaan berdasarkan hasil pada metode EOQ untuk produk

BJDC-SR 3,2 mm x $1.219 \mathrm{~mm}$ x $260 \mathrm{~mm}$ di PT. Ciptaunggul Karya Abadi adalah sebesar 70.589.399,-- selama dua belas bulan yang diperhitungkan.

c. Perhitungan Stok Pengaman

Tahapan selanjutnya adalah dengan mengidentifikasikan stok pengaman dengan menggunakan alat bantu statistika. Yaitu dengan melakukan perbandingan antara rata-rata dengan pemakaian bahan baku sebenarnya untuk kemudian diketahui penyimpangannya. Berikut adalah data penggunaan bahan baku BJDC-SR 3,2 mm x $1.219 \mathrm{~mm}$ x $260 \mathrm{~mm}$ selama 12 bulan yang diperhitungkan dengan standar deviasi seperti pada Tabel 4.

Tabel 4. Perhitungan standar deviasi

\begin{tabular}{ccccc}
\hline \multirow{2}{*}{ Bulan } & $\begin{array}{c}\text { Pemakaian } \\
\text { Bahan Baku }\end{array}$ & $\overline{\mathrm{X}}$ & $(\mathrm{X}-\overline{\mathrm{X}})$ & $(\mathrm{X}-\overline{\mathrm{X}})^{2}$ \\
\hline Januari & 150 & 75 & 75 & 5.655 \\
Februari & 124 & 75 & 49 & 2.402 \\
Maret & 138 & 75 & 63 & 4.006 \\
April & 98 & 75 & 23 & 521 \\
Mei & 0 & 75 & 75 & 5.595 \\
Juni & 0 & 75 & 75 & 5.595 \\
Juli & 48 & 75 & 27 & 739 \\
Agustus & 0 & 75 & 75 & 5.595 \\
September & 57 & 75 & 18 & 312 \\
Oktober & 112 & 75 & 37 & 1.377 \\
November & 95 & 75 & 20 & 418 \\
Desember & 76 & 75 & 1 & 2 \\
Jumlah & 898 & \multicolumn{2}{c}{ Jumlah } & 32.216 \\
\hline
\end{tabular}

Sumber: Hasil pengolahan data (2021)

Mencari $\overline{\mathrm{X}}$ menggunakan rumus sebagai berikut:

$\bar{X}=\frac{\mathrm{D}}{\mathrm{N}}=\frac{898}{12 \text { Bulan }}=75$ Lembar

Dimana:

$\mathrm{D}=$ Total kebutuhan selama 12 bulan

$\mathrm{n}=$ Total bulan pemakaian bahan baku.

Kemudian dilakukan perhitungan menggunakan rumus standar deviasi dengan menggunakan rumus sebagai berikut: 


$$
\begin{aligned}
\mathrm{SD} & =\sqrt{\sum \frac{(\mathrm{x}-\overline{\mathrm{x}})^{2}}{\mathrm{n}}} \\
& =\sqrt{\frac{32.216}{12 \text { bulan }}} \\
& =\sqrt{2.684,673} \\
& =51,814, \text { dibulatkan 52 lembar. }
\end{aligned}
$$

PT. Ciptaunggul Karya Abadi dalam pemenuhan permintaan adalah 95\% dan stok pengaman $5 \%$. Kemudian didapatkan $\mathrm{Z}$ dengan cara melihat pada tabel normal dan diapatkan nilai 1,65 standar deviasi dari rata-rata.

Stok Pengaman $\mathrm{Z} \sigma=\mathrm{Z} \times \mathrm{SD}$

$$
=1,65 \times 52
$$

$=85,8$, dibulatkan 86 lembar.

Jadi Safety Stock yang harus disediakan oleh PT. Ciptaunggul Karya Abadi adalah sebanyak 86 lembar per bulanya.

d. Perhitungan Titik Pemesanan Kembali

Untuk menghitung titik pemesanan bahan baku BJDC-SR 3,2 mm x $1.219 \mathrm{~mm}$ x $260 \mathrm{~mm}$ perlu diketahui terlebih dahulu waktu menunggu pemesanannya. Pada PT. Ciptaunggul Karya Abadi waktu tunggu yaitu selama 7 hari.

$$
\begin{aligned}
\mathrm{d} & =\frac{\mathrm{D}}{\mathrm{t}} \\
\mathrm{d} & =\frac{898}{312} \\
& =2,87 \text { lembar. }
\end{aligned}
$$

Keterangan:

$\mathrm{d}=$ Jumlah pemakaian per hari.

$\mathrm{D}=$ Kebutuhan bahan baku satu tahun.

$\mathrm{t}=$ Waktu kerja per hari selama satu tahun

Maka, titik pemesanan kembali bahan baku BJDC-SR 3,2 mm x $1.219 \mathrm{~mm}$ x $260 \mathrm{~mm}$ adalah

ROP = Pemakain bahan baku per hari (d) $\mathrm{x}$ Lead time

$=2,87 \times 7$ hari

$=20,09$ dibulatkan 21 lembar

Jadi titik pemesanan kembali yang harus dilakukan PT. Ciptaunggul Karya Abadi yaitu ketika bahan baku BJDC-SR 3,2 $\mathrm{mm}$ x $1.219 \mathrm{~mm}$ x $260 \mathrm{~mm}$ berjumlah 21 lembar.

e. Hasil Perbandingan Perhitungan Perusahaan dengan hasil EOQ

Berdasarkan hasil perhitungan yang telah didapatkan, maka dilakukan perbandingan dengan kebijakan yang selama ini diterapkan oleh perusahaan. Berikut ini adalah hasil perbandingan kebijakan perusahaan dengan hasil pada EOQ seperti pada Tabel 5.

Tabel 5. Hasil perbandingan

\begin{tabular}{clccc}
\hline No & \multicolumn{1}{c}{ Keterangan } & Perhitungan Perusahaan & EOQ \\
\hline 1. & Pembelian rata-rata & per & 225 Lembar & 621 Lembar \\
2. & sekali pesan & 4 & 2 \\
F. & Total biaya persedianan & Rp. 110.264.235 & Rp. 70.589 .399 \\
4. & Safety stock per bulan & - & 86 Lembar \\
5. & Re Order Point & - & 21 Lembar \\
\hline
\end{tabular}

Sumber: Hasil pengolahan data (2021)

Berdasarkan hasil yang ditunjukkan pada Tabel 5. dapat diketahui terjadi penghematan biaya sebesar Rp. 39.674.836. Dengan hasil perhitungan tersebut dan juga penghematan yang terjadi, sepatutnya perusahaan dapat menggunakan dan menerapkan hasil yang didapatkan tersebut. Hal ini dikarenakan perusahaan dapat memenuhi jumlah kebutuhan bahan baku untuk produk BJDC-SR 3,2 $\mathrm{mm} \times 1.219 \mathrm{~mm} \times 260 \mathrm{~mm}$.

\section{Kesimpulan}

Berdasarkan hasil yang didapatkan, dapat diketahui terdapat perbeadan antara hasil pada perhitungan menggunakan EOQ dengan sistem yang diterapkan oleh perusahaan. Hasil pada EOQ dinilai lebih baik 
karena dibandingkan dari segi biaya terjadi penghematan yang menjadi indikator efisiensi perusahaan. Selain itu, penentuan stok pengaman dan titik pemesanan kembali pun telah ditentukan, sementara pada kebijakan yang diterapkan perusahaan hal tersebut belum tersedia. Oleh sebab itu, melalui penerapan EOQ PT. Ciptaunggul Karya Abadi telah mengalami peningkatan dalam proses pengendalian persediaannya. Hal tersebut dikarenakan perbandingan yang dilakukan. Dari hal tersebut, diharapkan perusahaan dapat menerapkan hasil yang didapatkan pada penelitian ini guna mengefisiensikan dan mengoptimalkan pengendalian persediaannya.

\section{Referensi}

[1] I. Rizkya dan Fernando, "Optimalisasi persediaan bahan baku atap spandex dengan metode Q," $J$. Sist. Tek. Ind., vol. 23, no. 1, pp. 1-8, 2021, doi: 10.32734/jsti.v23i1.4906.

[2] Sofiyanurriyanti, "Analisa persediaan bahan baku mengunakan metode EOQ (Economy Order Quantity) di CV. Alfa Nafis,” J. Ilm. Rekayasa, vol. 10, no. 2, pp. 65-70, 2017, doi: 10.21107/rekayasa.v10i2.3606.

[3] R. Wahyudi, "Analisis pengendalian persediaan barang berdasarkan metode eoq di Toko Era Baru Samarinda," Ejournal Ilmu Admistrasi Bisnis, vol. 2, no. 1, pp. 162-173, 2015, [Online]. Available: http://ejournal.adbisnis.fisip-unmul.ac.id/site/wp-content/uploads/2015/03/E-journaL PDF (03-0415-03-58-13).pdf.

[4] S. N. Hadi dan S. Khairawati, "Analisis implementasi manajemen persediaan bahan baku pada industri kuliner dalam perspektif etika bisnis islam," J. Manaj. dan Bisnis Performa, vol. 17, no. 2, pp. 57-69, 2020, doi: 10.29313/performa.v17i1.7265.

[5] V. Elviana dan A. Suryadi, "Perencanaan dan pengendalian persediaan bahan baku pail cat menggunakan metode material requirment planning (MRP) pada PT. XYZ," Juminten J. Manaj. Ind. dan Teknol., vol. 01, no. 04, pp. 163-172, 2020.

[6] O. E. Andira, "Analisis persediaan bahan baku tepung terigu menggunakan metode eoq (economic order quantity) pada Roti Puncak Makassar,” J. Ilmiah Ekon. Bisnis, vol. 21, no. 3, pp. 201-208, 2016.

[7] Hotasadi, "Penerapan Metode economic order quantity (eoq) dalam pengendalian persediaan bahan baku pada LE’TaT Bakery,” J. ACSY Politek. Sekayu, vol. 6, no. 2, pp. 87-98, 2017.

[8] K. Hidayat, J. Efendi, dan R. Faridz, "Analisis pengendalian persediaan bahan baku kerupuk mentah potato dan kentang keriting menggunakan metode economic order quantity (EOQ)," Performa Media Ilm. Tek. Ind., vol. 18, no. 2, pp. 125-134, 2019, doi: 10.20961/performa.18.2.35418.

[9] D. B. Permadi, L. D. Indrasari, dan A. Y. Tripariyanto, "Analisis efektifitas stok barang pada PT . Gading Murni Surabaya menggunakan metode EOQ," J. Ilm. Tek. dan Manaj. Ind. Univ. Kadiri, vol. 5, no. 1, pp. 67-79, 2021.

[10] A. Gunawan, Kusnadi, dan Hamdani, "Analisis produktivitas tenaga kerja dengan metode E. Mundel pada CV. Mulia Tata Sejahtera," J. Serambi Eng., vol. 6, no. 3, pp. 2135-2143, 2021.

[11] T. H. Handoko, Dasar-Dasar Manajemen Produksi dan Operasi, 1st ed. Yogyakarta: BPFE Yogyakarta, 2011.

[12] T. H. Handoko, Dasar-Dasar Manajemen Produksi dan Operasi, 1st ed. Yogyakarta: BPFE Yogyakarta, 2015.

[13] H. Jay and B. Render, Manajemen Operasi, 9th ed. Jakarta: Salemba Empat, 2010.

[14] H. Jay and B. Render, Manajemen Operasi, 9th ed. Jakarta: Salemba Empat, 2011.

[15] A. Thomas dan K. Suhada, "Pengendalian Persediaan bahan baku produk active speaker menggunakan algoritma wagner within di PT Hartono Istana Teknologi," J. Integr. Syst., vol. 3, no. 1, pp. 59-71, 2020. 